\title{
Natural streamflow simulation for two largest river basins in Poland: a baseline for identification of flow alterations
}

\author{
Mikołaj Piniewski ${ }^{1,2}$ \\ ${ }^{1}$ Warsaw University of Life Sciences, Warsaw, Poland \\ ${ }^{2}$ Potsdam Institute of Climate Impact Research, Potsdam, Germany \\ Correspondence to: Mikołaj Piniewski (m.piniewski@levis.sggw.pl) \\ Published: 12 May 2016
}

\begin{abstract}
The objective of this study was to apply a previously developed large-scale and high-resolution SWAT model of the Vistula and the Odra basins, calibrated with the focus of natural flow simulation, in order to assess the impact of three different dam reservoirs on streamflow using the Indicators of Hydrologic Alteration (IHA). A tailored spatial calibration approach was designed, in which calibration was focused on a large set of relatively small non-nested sub-catchments with semi-natural flow regime. These were classified into calibration clusters based on the flow statistics similarity. After performing calibration and validation that gave overall positive results, the calibrated parameter values were transferred to the remaining part of the basins using an approach based on hydrological similarity of donor and target catchments. The calibrated model was applied in three case studies with the purpose of assessing the effect of dam reservoirs (Włocławek, Siemianówka and Czorsztyn Reservoirs) on streamflow alteration. Both the assessment based on gauged streamflow (Before-After design) and the one based on simulated natural streamflow showed large alterations in selected flow statistics related to magnitude, duration, high and low flow pulses and rate of change. Some benefits of using a large-scale and highresolution hydrological model for the assessment of streamflow alteration include: (1) providing an alternative or complementary approach to the classical Before-After designs, (2) isolating the climate variability effect from the dam (or any other source of alteration) effect, (3) providing a practical tool that can be applied at a range of spatial scales over large area such as a country, in a uniform way. Thus, presented approach can be applied for designing more natural flow regimes, which is crucial for river and floodplain ecosystem restoration in the context of the European Union's policy on environmental flows.
\end{abstract}

\section{Introduction}

The Vistula and the Odra basins (VOB), whose total area in Poland, Germany, Czech Republic, Slovakia, Ukraine and Belarus amounts to $313000 \mathrm{~km}^{2}$ are among the five largest river basins in the European Union. To date, the VOB has not been modelled in a comparable manner as the remaining three basins from the EU's top five: the Danube (Pagliero et al., 2014), the Rhine or the Elbe (Huang et al., 2015). The VOB is covered by larger-scale applications, e.g. for the Baltic Sea Basin Donnelly et al. (2014) or entire Europe Abbaspour et al. (2015), but they offer much coarser resolution than it would be desired to address locally specific water resource problems. Such problems can be more accurately ad- dressed by a large-scale and high-resolution model that is tailored for this area.

The overwhelming majority of large river basins in the world are currently to some extent impacted by human pressure that usually causes departures of discharge from natural to altered conditions (Richter et al., 1997). The largest impact on streamflow regime is usually attributed to dam reservoirs, although the irrigation systems, inter-basin transfers, point source discharges and withdrawals can also have a considerable effect. The degree of flow alteration in the VOB is moderate compared to western Europe or other worlds regions (cf. Milliman et al., 2008) and it is possible to identify both a subset of near-pristine benchmark catchments and heavilyregulated catchments. 
Assessment of anthropogenic streamflow alteration and identification of baseline streamflow conditions and their range of variability across different scales, is fundamental to water resources management, understanding subsequent ecological effects, and designing environmental flows (Poff et al., 2010). Flow gauge-based approaches to assessing streamflow alteration are popular, but their large-scale applicability is limited due to a low density of gauging stations or missing data records. An alternative approach is to apply a hydrological model that can prove useful in diverse ways. For example, a model that does not account for water management but is tailored for simulation of natural flows can serve as a tool providing a rapid estimate of the baseline hydrological conditions, which is the first step in a popular framework for assessing environmental flows called ELOHA (Ecological Limits of Hydrologic Alteration) framework (Poff et al., 2010).

The main objective of this study is to apply a previously developed large-scale and high-resolution SWAT model of the VOB, calibrated with the focus of natural flow simulation, in order to assess the impact of three different dam reservoirs on streamflow using the Indicators of Hydrologic Alteration (IHA).

\section{Natural streamflow simulation with SWAT}

A detailed description of the model setup, calibration protocol and model evaluation has been published elsewhere (Piniewski et al., 2016). Here we provide a short summary essential for better understanding of the core part related to the assessment of flow alteration.

\subsection{Model inputs and calibration approach}

SWAT is a process-based, semi-distributed, continuous-time hydrological model that simulates the movement of water, sediment and nutrients on a catchment scale with a daily time step (Arnold et al., 1998).

The whole area of the VOB was divided into 2633 subbasins and 21311 Hydrological Response Units. The 1951$20135 \mathrm{~km}$ resolution daily climate data were obtained from the CHASE-PL Forcing Data (CPLFD-GDPT5), the gridded daily temperature and precipitation dataset (Berezowski et al., 2015, 2016). The SUFI-2 algorithm (Abbaspour et al., 2004) within the SWAT-CUP software package was used for model calibration. We used Kling-Gupta Efficiency (KGE) as the objective function (Gupta et al., 2009). We selected 1991-2000 as the model calibration period and 2001-2010 as the validation period.

A spatial calibration approach accompanied by a parameter regionalisation scheme that leads to simulation of natural streamflow in the whole model domain was designed. The first step of the calibration protocol was selection of small, non-nested catchments located in the VOB, with relatively undisturbed flow regimes, the so-called "benchmark" catch- ments. 80 catchments fulfilling the specified criteria were left. In the next step benchmark catchments were grouped into clusters of similar flow regime properties. The rationale was to derive a smaller number of homogeneous calibration areas, each of which would have its own parameter set. We have followed the statistical approach applied in previous works on natural flow regime classifications (Mackay et al., 2014) in order to do the cluster analysis. Eight flow regime clusters showed in Fig. 1 were distinguished.

The total area of 80 benchmark catchments constitutes only $25 \%$ of the VOB. Therefore a regionalisation strategy was necessary to transfer calibrated parameter values across the entire VOB. We used the hydrological distance approach (He et al., 2011), in which hydrological similarity was evaluated based on a set of climatic-physiographic properties of the donor and target catchments. This approach was evaluated by validating the model at two most downstream gauging stations on the two investigated rivers.

\subsection{Model performance evaluation}

The model performance at 80 benchmark gauges as well as at two most downstream basin outlets is illustrated in Fig. 2. Median KGE across all benchmark catchments was equal to 0.7 and 0.63 for calibration and validation period, respectively. Even though there are individual catchments with rather poor results (KGE below 0.4), the majority of KGE values falls into a satisfactory range. Figure $2 b$ and $c$ also shows that the parameter regionalisation approach worked very well: calibration results at two most downstream gauges are significantly better than the average results for the benchmark catchments.

The calibrated SWAT model of the VOB was then used to run a simulation for the whole period of availability of CPLFD data. The resulting output dataset CPL-NH (CHASE-PL - Natural Hydrology), consisting of monthly sub-basin water balance components and daily (natural) streamflow records for 2633 sub-basins and reaches, for the time period 1954-2013 is stored in an open online research data archive 3TU.Datacentrum (Piniewski et al., 2015). For further analysis, we have extracted output from this dataset.

\section{Assessment of flow alteration caused by dams}

In order to illustrate the effect of dam reservoirs on downstream flow alteration we selected three reservoirs situated in different parts of Poland (Fig. 1) and having different characteristics (Table 1). Selected reservoirs differ with respect to upstream catchment area, dam height, construction year, capacity and dominating functions. All of them were associated with the nearest flow gauge situated downstream of a dam and with respective model outlet for which simulated daily flows were available. The Nature Conservancy's IHA program (Mathews and Richter, 2007) was applied to calculate 33 flow statistics based on pre-dam and post-dam ob- 


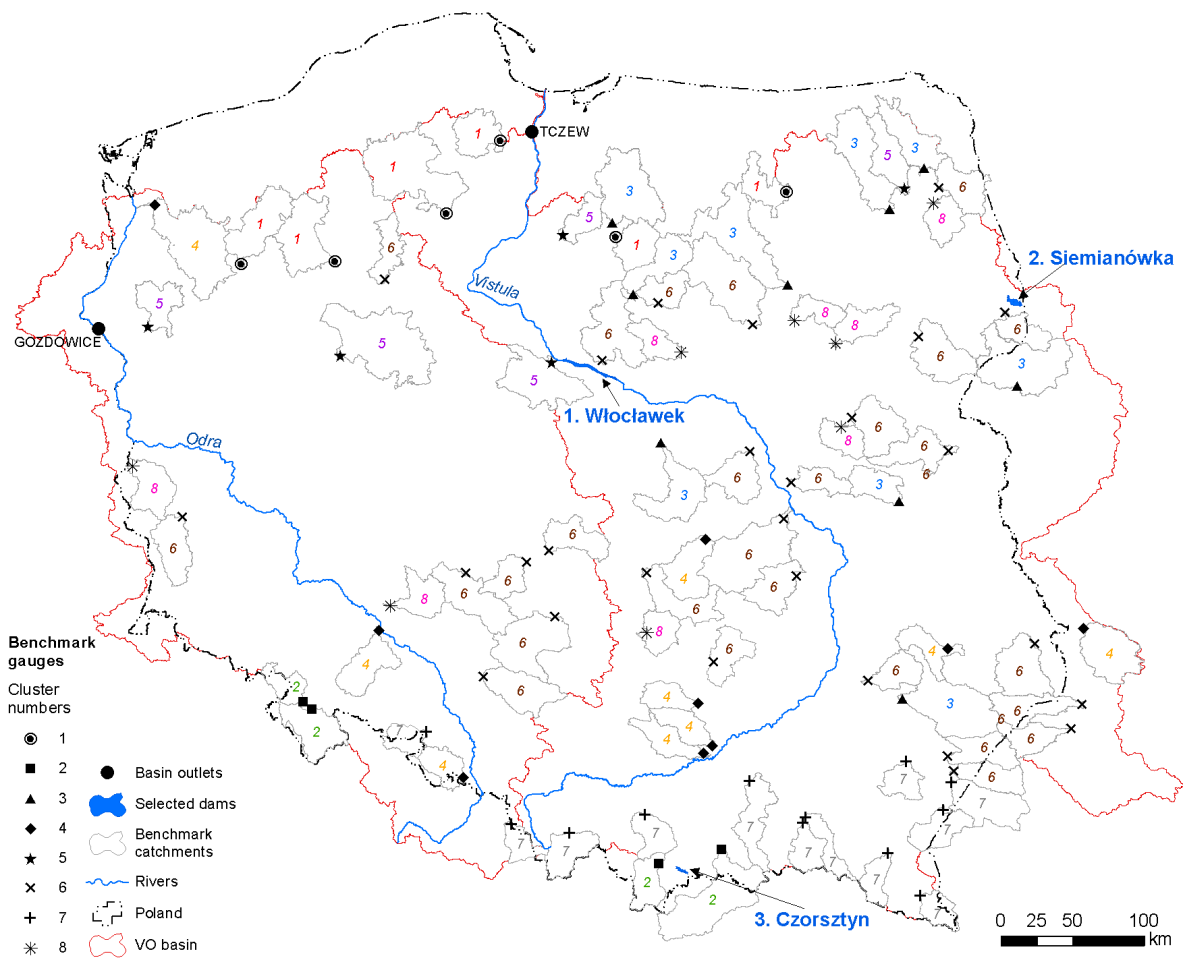

Figure 1. Division of benchmark catchments into 8 clusters and location of three studied dam reservoirs (modified after Piniewski et al., 2016).

served and modelled streamflow data. A number of comparisons were made, each of which served a different purpose:

1. Comparison of pre-impact and post-impact flow statistics using gauged flows provides an estimate of the magnitude of flow alteration due to dam effect. This can be referred to as the Before-After (BA) design (Peñas et al., 2016).

2. Comparison of pre-impact and post-impact flow statistics using simulated flows provides an estimate of the flow alteration due to climate effect.

3. Comparison of pre-impact gauged and simulated flow statistics is a way of model validation.

4. Comparison of post-impact gauged and simulated flow statistics is an alternative to the BA design. It can be referred to as the Control-Impact (CI) design (Peñas et al., 2016), where modelled flows serve as a control.

The IHA statistics refer to different aspects of flow regime (magnitude, duration, timing, high and low flow pulses, rate of change). For illustrative purposes three example statistics selected for each reservoir are discussed below.

\subsection{Włocławek Reservoir}

Constructed in 1970, Włocławek Reservoir with a surface area of $70 \mathrm{~km}^{2}$ is the largest reservoir in Poland. It also has the largest upstream catchment area of $171000 \mathrm{~km}^{2}$. Since the ratio of capacity to inflow is relatively low, reservoir operation does not strongly affect such parameters as seasonal flows, extreme flows or timing. However, the parameters related to the rate of change (rise rate, fall rate and number of flow reversals) are affected, as shown in Fig. 3a-c. The analysis based on gauged flows demonstrates that all these parameters have at least doubled after dam construction. At the same time there is no significant change in the same parameters assessed using modelled flows, which shows that the natural climatic variability did not affect them. Comparison of pre-dam observed and simulated data shows on the other hand that the SWAT-based rate of change parameters, particularly fall rate and number of reversals, are underestimated. Thus, the effect of Włocławek dam assessed following the CI design is presumably over-estimated.

\subsection{Siemianówka Reservoir}

Constructed in 1992, Siemianówka Reservoir with a surface area of $32.5 \mathrm{~km}^{2}$ is the third largest reservoir in Poland. It also has relatively small upstream catchment area of $1100 \mathrm{~km}^{2}$. This is a lowland catchment situated mainly in Belarus. Due to a relatively large ratio of capacity to inflow, a long list of flow parameters are affected by this dam. Three of them showing significant impacts were selected for illustrative purposes: mean December flow, 1-day maximum flow 
(a) KGE values at benchmark gauges

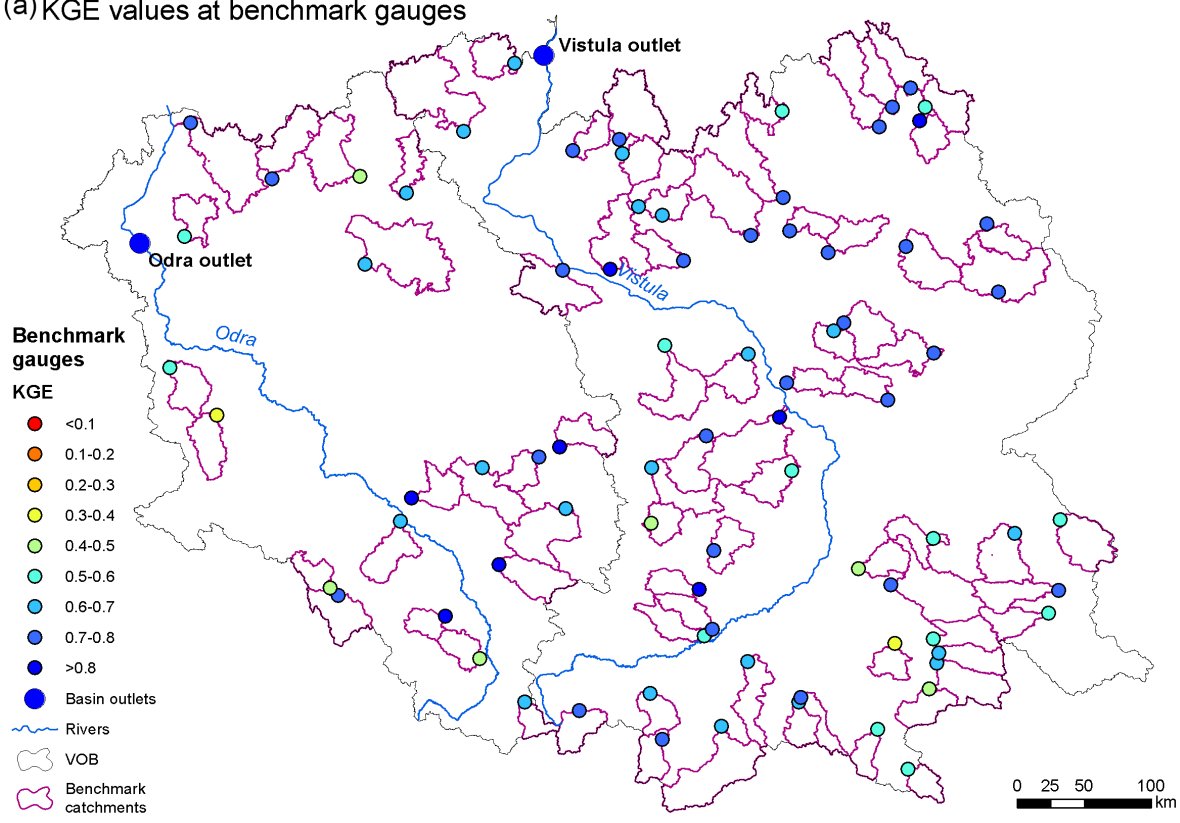

(b) Simulated and observed flow at Gozdowice gauge on the Odra

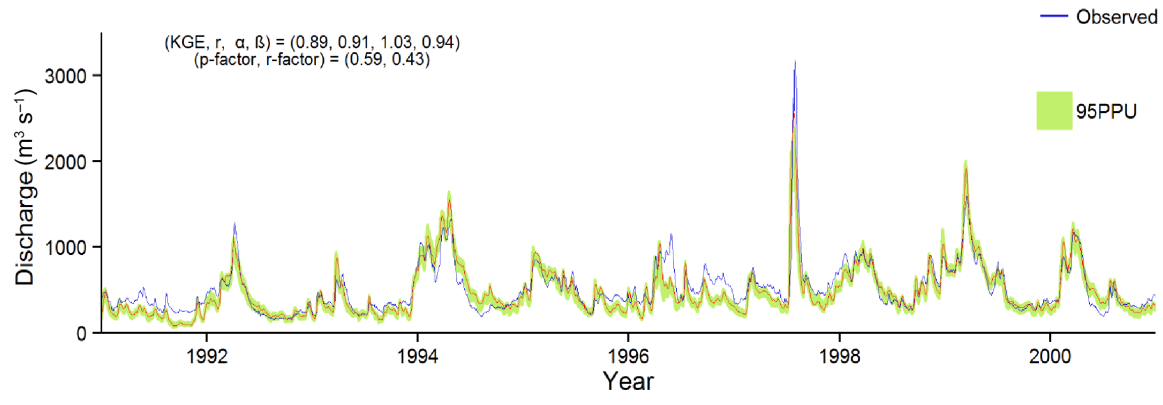

(c) Simulated and observed flow at Tczew gauge on the Vistula

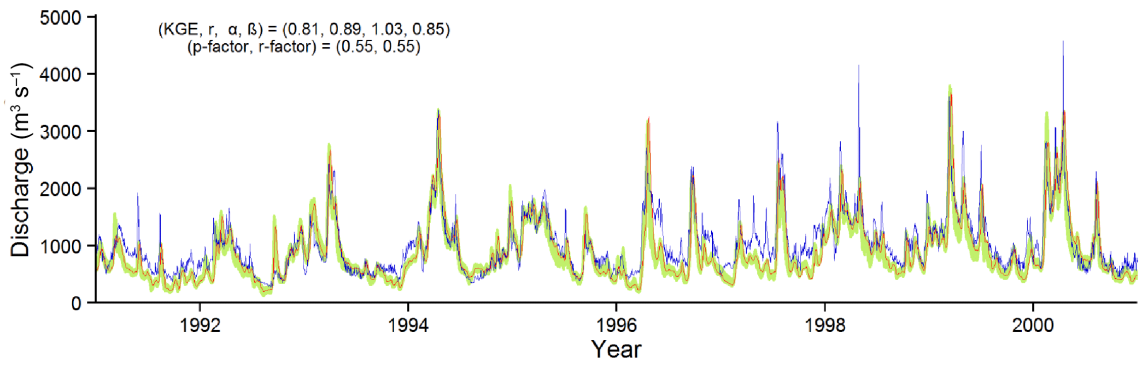

Figure 2. Calibration results: KGE values at benchmark gauges (a), simulated and observed flows at Gozdowice gauge on the Odra (b) and at Tczew gauge on the Vistula (c) (modified after Piniewski et al., 2016).

and high pulse number (Fig. 3d-f). The analysis following the BA design demonstrates that post-dam period was not homogeneous, i.e. the pattern of streamflow indices for the periods 1992-1999 and 2000-2007 was considerably different. For example, an abrupt increase in December flows after dam construction lasted until approximately year 1999, after which December flows were generally lower than in the pre-dam period. As with Włocławek Reservoir, there is no significant change in the studied parameters assessed using modelled flows, which shows that the natural climatic variability did not affect them. Visual comparison of pre-dam observed and simulated data shows on the other hand a moderate agreement between SWAT-based and gauge-based parameters. The effect of Siemianówka dam assessed by comparing post-impact observed and modelled data is different in different sub-periods. For example, high pulse number was 
Table 1. Main features of investigated reservoirs.

\begin{tabular}{|c|c|c|c|c|c|c|c|c|}
\hline Reservoir & River & Gauge & $\begin{array}{l}\text { Catchment } \\
\text { area }\left[10^{3} \mathrm{~km}^{2}\right]\end{array}$ & $\begin{array}{l}\text { Dam } \\
\text { height }[\mathrm{m}]\end{array}$ & $\begin{array}{l}\text { Construction } \\
\text { end year }\end{array}$ & $\begin{array}{l}\text { Capacity } \\
{\left[10^{6} \mathrm{~m}^{3}\right]}\end{array}$ & $\begin{array}{l}\text { Power plant } \\
\text { capacity } \\
{[\mathrm{MW}]}\end{array}$ & $\begin{array}{l}\text { Dominating } \\
\text { functions }\end{array}$ \\
\hline Włocławek & Wisła & Włocławek & 171 & 20 & 1970 & 408 & 160 & $\begin{array}{l}\text { energy, recre- } \\
\text { ation }\end{array}$ \\
\hline Siemianówka & Narew & Bondary & 1.10 & 9 & 1992 & 79.5 & 0.16 & $\begin{array}{l}\text { nature } \\
\text { protection, } \\
\text { irrigation, } \\
\text { recreation }\end{array}$ \\
\hline Czorsztyn & Dunajec & $\begin{array}{l}\text { Sromowce } \\
\text { Wyżne }\end{array}$ & 1.3 & 56 & 1997 & 232 & 92 & $\begin{array}{l}\text { flood protec- } \\
\text { tion, energy }\end{array}$ \\
\hline
\end{tabular}
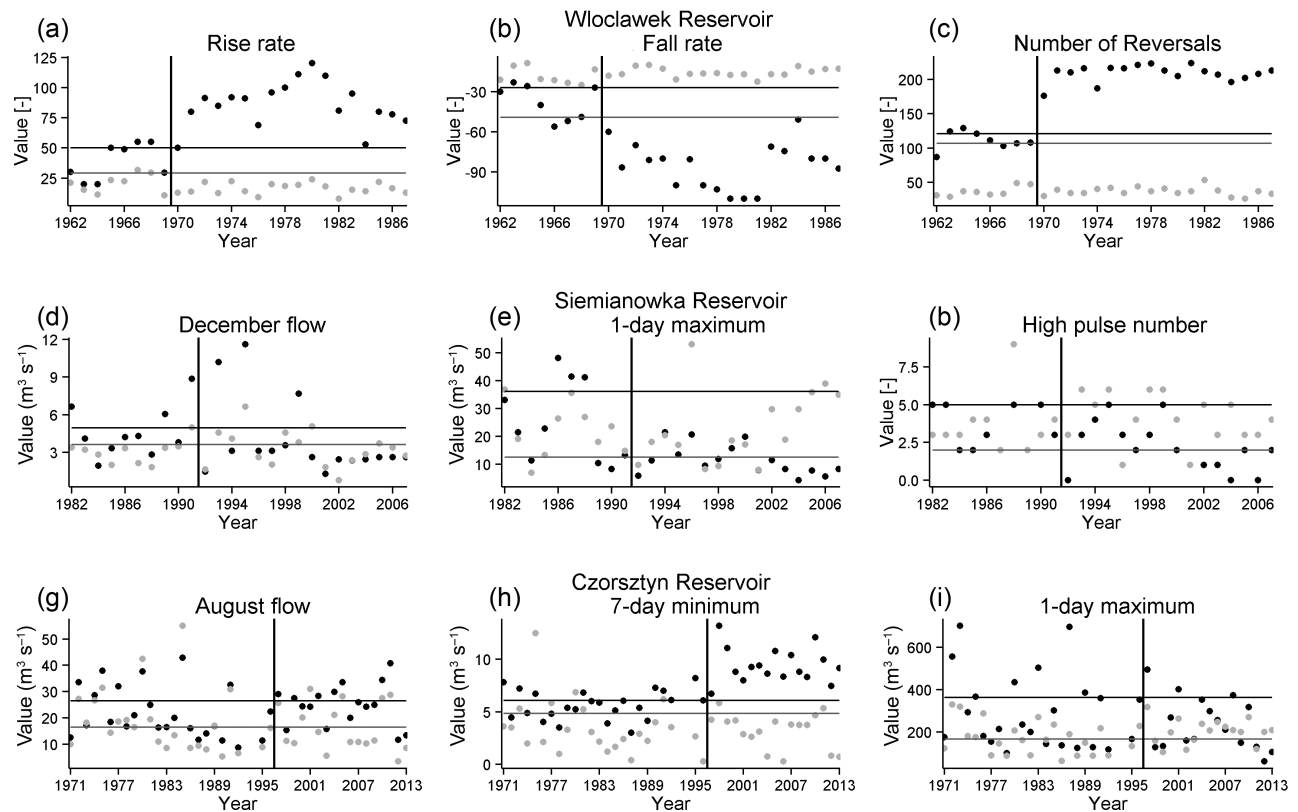

- Observed - Simulated -25 th percentile (pre-dam obs.) $\quad$ - 75 th percentile (pre-dam obs.)

Figure 3. The effect of three dam reservoirs: Włocławek, Siemianówka and Czorsztyn on streamflow alteration assessed using observed and simulated flows. Black vertical line denotes the construction year of each reservoir. The 25th and 75 th percentiles of the flow statistics were calculated based on pre-dam observed flows and delineate the likely interval of natural variability of a given statistics.

significantly lower for the observed flows than for the simulated flows in the sub-period 1992-1999, while in the later period they were similar.

\subsection{Czorsztyn reservoir}

Constructed in 1997, Czorsztyn Reservoir with a storage capacity of 232 millions $\mathrm{m}^{3}$ is the third largest reservoir in Poland (with respect to capacity). In contrast to Włocławek and Siemianówka it is situated in the mountains, on the River Dunajec characterised by a more dynamic flow regime. Three parameters showing relatively large impacts related to dam construction were selected for illustrative purposes: mean
August flow, 1-day maximum flow and 7-day minimum flow (Fig. 3g-i). The analysis based on gauged flows demonstrates that August mean flows and 7-day minimum flows increased and 1-day maximum flows decreased (including their variability) after dam construction. In contrast to two previous examples, the natural climatic variability seems to have affected streamflow as well. For example, simulated mean August flows were significantly lower, while simulated 1-day maximum flows had a considerably lower variability in the post-dam period as compared to the pre-dam period. Visual comparison of pre-dam observed and simulated data shows on the other hand a high agreement between SWATbased and gauge-based August flows, and an underestima- 
tion of minimum and maximum flows by SWAT. The effect of Czorsztyn dam assessed in the CI design suggests a higher dam impact than when assessed in temporal comparison, in particular for August flow and 7-day minimum flow. While in the first case this statement seems to be true (because of good performance of SWAT in simulating August flows), in the latter it is probably wrong (because of underestimation of minimum flows by SWAT in the pre-dam period).

\section{Discussion and outlook}

The spatial calibration approach developed here in order to simulate natural discharge over two large river basins is applicable in other geographical settings, particularly for areas in which the degree of flow alteration is moderate (as in Poland), i.e. it is possible to identify both a subset of nearpristine benchmark catchments and heavily-regulated catchments. An approximate indication of such regions over the world can be made based on the global distribution of deficit watersheds of Milliman et al. (2008) or on the global distribution of aging of continental runoff in response to large reservoir impoundment (Vörösmarty and Sahagian, 2000). For river basins that are entirely near-pristine this approach would not bring much benefit, as the gauged hydrology is already natural. In contrast, for extremely regulated river basins, this approach would not work because of insufficient number of unaltered benchmark catchments.

This study showed that three different reservoirs caused alteration of different flow regime characteristics. The added value of using the large-scale high-resolution hydrological model for assessing flow alteration is manifold. The assessment using gauged flows is probably more accurate, but in many cases gauges can be situated far downstream from a dam (or another source of alteration, such as point source or abstraction), and thus the direct effect is dampened. A common issue with gauged flows are missing data, which can be supplemented by simulated streamflow. Finally, comparison of pre-dam and post-dam gauged flow data (BA design) carries the danger of ignoring the effect of natural climatic variability. In this respect, the modelled flows can serve as the proxy of a control gauge (CI design) within the full BeforeAfter-Control-Impact (BACI) design, the preferred design of assessing flow alteration (Peñas et al., 2016). As shown in this study and elsewhere (Shrestha et al., 2014), care needs to be taken as far as the reliability of modelled flow statistics is concerned. If the model is able to predict the variability of a given parameter in the pre-impact period, it can be reliably used in the Control-Impact design. As with the August flow for Czorsztyn Reservoir, there was a good agreement for this parameter during the pre-impact period, and thus one could conclude that the dam effect assessed using the BA design was underestimated. The reason was that this design neglected the fact that post-impact streamflow was naturally lower than the pre-impact streamflow in August.
In Poland, environmental flows have been for a long time identified with minimum low flow thresholds. Due to the EU Water Framework Directive and its environmental flow policy (Acreman et al., 2009) this situation is gradually changing, and more importance is given to flow requirements of valuable ecosystems such as riparian wetlands (Piniewski et al., 2014). It is anticipated that designing environmental flows from dams will sooner or later become an important topic in Poland. Thus, a model simulating baseline (natural) hydrology in $90 \%$ of the country may be a useful tool in guiding this process, since a similar analysis as performed here for only three reservoirs can be easily extended over all major sources of flow alteration.

\section{Data availability}

The underlying research data: (1) CHASE-PL Natural Hydrology dataset (CPL-NH), and (2) CHASE-PL Forcing Data: Gridded Daily Precipitation \& Temperature Dataset $5 \mathrm{~km}$ (CPLFD-GDPT5), can be accessed for free at 3TU.Datacentrum repository (https://data.3tu.nl/repository/ uuid:b8ab4f5f-f692-4c93-a910-2947aea28f42 and doi:10.4121/uuid:e939aec0-bdd1-440f-bd1e-c49ff10d0a07, respectively).

Acknowledgements. Support of the project CHASE-PL (Climate change impact assessment for selected sectors in Poland) of the Polish-Norwegian Research Programme is gratefully acknowledged. Help of Mateusz Szcześniak and other colleagues from the CHASE-PL project is highly appreciated. The author is grateful for support to the Alexander von Humboldt Foundation and to the Ministry of Science and Higher Education of the Republic of Poland.

\section{References}

Abbaspour, K., Rouholahnejad, E., Vaghefi, S., Srinivasan, R., Yang, H., and Klove, B.: A continental-scale hydrology and water quality model for Europe: Calibration and uncertainty of a high-resolution large-scale SWAT model, J. Hydrol., 524, 733$752,2015$.

Abbaspour, K. C., Johnson, C. A., and van Genuchten, M. T.: Estimating uncertain flow and transport parameters using a sequential uncertainty fitting procedure, Vadose Zone J., 3, 1340-1352, 2004.

Acreman, M., Aldrick, J., Binnie, C., Black, A., Cowx, I., Dawson, H., Dunbar, M., Extence, C., Hannaford, J., Harby, A., Holmes, N., Jarritt, N., Old, G., Peirson, G., Webb, J., and Wood, P.: Environmental flows from dams: the Water Framework Directive, Proceedings of the Institution of Civil Engineers - Engineering Sustainability, 162, 13-22, 2009.

Arnold, J. G., Srinivasan, R., Muttiah, R. S., and Williams, J. R.: Large-area hydrologic modeling and assessment: Part I. Model development, J. Am. Water Resour. As., 34, 73-89, 1998.

Berezowski, T., Szcześniak, M., Kardel, I., Michałowski, R., and Piniewski, M.: CHASE-PL Forcing Data - Gridded Daily Precipitation Temperature Dataset (CPLFD-GDPT5), Dataset on 
3TU.Datacentrum, doi:10.4121/uuid:e939aec0-bdd1-440f-bd1ec49ff10d0a07, 2015.

Berezowski, T., Szcześniak, M., Kardel, I., Michalowski, R., Okruszko, T., Mezghani, A., and Piniewski, M.: CPLFDGDPT5: High-resolution gridded daily precipitation and temperature data set for two largest Polish river basins, Earth Syst. Sci. Data, 8, 127-139, doi:10.5194/essd-8-127-2016, 2016.

Donnelly, C., Yang, W., and Dahné, J.: River discharge to the Baltic Sea in a future climate, Climatic Change, 122, 157-170, 2014.

Gupta, H. V., Kling, H., Yilmaz, K. K., and Martinez, G. F.: Decomposition of the mean squared error and NSE performance criteria: Implications for improving hydrological modelling, J. Hydrol., 377, 80-91, 2009.

He, Y., Bárdossy, A., and Zehe, E.: A review of regionalisation for continuous streamflow simulation, Hydrol. Earth Syst. Sci., 15, 3539-3553, doi:10.5194/hess-15-3539-2011, 2011.

Huang, S., Krysanova, V., and Hattermann, F.: Projections of climate change impacts on floods and droughts in Germany using an ensemble of climate change scenarios, Reg. Environ. Change, 15, 461-473, 2015.

Mackay, S. J., Arthington, A. H., and James, C. S.: Classification and comparison of natural and altered flow regimes to support an Australian trial of the Ecological Limits of Hydrologic Alteration framework, Ecohydrology, 7, 1485-1507, 2014.

Mathews, R. and Richter, B. D.: Application of the Indicators of Hydrologic Alteration Software in Environmental Flow Setting, JAWRA Journal of the American Water Resources Association, 43, 1400-1413, 2007.

Milliman, J., Farnsworth, K., Jones, P., Xu, K., and Smith, L.: Climatic and anthropogenic factors affecting river discharge to the global ocean, 1951-2000, Global Planet. Change, 62, 187-194, 2008.

Pagliero, L., Bouraoui, F., Willems, P., and Diels, J.: Large-Scale Hydrological Simulations Using the Soil Water Assessment Tool, Protocol Development, and Application in the Danube Basin, J. Environ. Qual., 43, 145-154, 2014.
Peñas, F., Barquín, J., and Álvarez, C.: Assessing hydrologic alteration: Evaluation of different alternatives according to data availability, Ecol. Indic., 60, 470-482, 2016.

Piniewski, M., Okruszko, T., and Acreman, M. C.: Environmental water quantity projections under market-driven and sustainability-driven future scenarios in the Narew basin, Poland, Hydrol. Sci. J., 59, 916-934, 2014.

Piniewski, M., Szcześniak, M., Kardel, I., and Berezowski, T.: CHASE-PL Natural Hydrology dataset (CPL-NH), Dataset on 3TU.Datacentrum, doi:10.4121/uuid:b8ab4f5f-f692-4c93-a9102947aea28f42, 2015.

Piniewski, M., Szcześniak, M., Kardel, I., Berezowski, T., Okruszko, T., Srinivasan, R., Vikhamar Shuler, D., and Kundzewicz, Z.: Modelling water balance and streamflow at high resolution in the Vistula and Odra basins, Hydrol. Sci. J., submitted, 2016.

Poff, N. L., Richter, B. D., Arthington, A. H., Bunn, S. E., Naiman, R. J., Kendy, E., Acreman, M., Apse, C., Bledsoe, B. P., Freeman, M. C., Henriksen, J., Jacobson, R. B., Kennen, J. G., Merritt, D. M., O'Keeffe, J. H., Olden, J. D., Rogers, K., Tharme, R. E., and Warner, A.: The ecological limits of hydrologic alteration (ELOHA): a new framework for developing regional environmental flow standards, Freshwater Biol., 55, 147-170, 2010.

Richter, B., Baumgartner, J., Wigington, R., and Braun, D.: How much water does a river need?, Freshwater Biol., 37, 231-249, 1997.

Shrestha, R. R., Peters, D. L., and Schnorbus, M. A.: Evaluating the ability of a hydrologic model to replicate hydro-ecologically relevant indicators, Hydrol. Process., 28, 4294-4310, 2014.

Vörösmarty, C. J. and Sahagian, D.: Anthropogenic Disturbance of the Terrestrial Water Cycle, BioScience, 50, 753-765, 2000. 